\section{BMJ Open} Ophthalmology

\title{
Estimating the magnitude of diabetes mellitus and diabetic retinopathy in an older age urban population in Pune, western India
}

Sucheta Kulkarni, ${ }^{\oplus 1}$ Shridevi Kondalkar, ${ }^{2}$ Islay Mactaggart, ${ }^{2}$ B R Shamanna, ${ }^{3}$ Azher Lodhi, ${ }^{1}$ Rohit Mendke, ${ }^{1}$ Jitesh Kharat, ${ }^{1}$ Rajesh Kapse, ${ }^{1}$ Kuldeep Dole, ${ }^{1}$ Madan Deshpande ${ }^{1}$

To cite: Kulkarni S, Kondalkar S, Mactaggart I, et al. Estimating the magnitude of diabetes mellitus and diabetic retinopathy in an older age urban population in Pune, western India. BMJ Open Ophthalmology 2019;4:e000201. doi:10.1136/ bmjophth-2018-000201

- Additional material is published online only. To view please visit the journal online (http://dx.doi.org/10.1136/ bmjophth-2018-000201).

Received 8 August 2018 Revised 12 December 2018 Accepted 29 January 2019

D) Check for updates

C Author(s) (or their employer(s)) 2019. Re-use permitted under CC BY-NC. No commercial re-use. See rights and permissions. Published by BMJ.

${ }^{1}$ Department of Community Ophthalmology, PBMA's H. V. Desai Eye Hospital, Pune, Maharashtra, India

${ }^{2}$ Clinical Research, The London School of Hygiene \& Tropical Medicine, London, UK ${ }^{3}$ Research Services, Prashasa Health Consultants Pvt. Ltd, Hyderabad, Telangana, India

Correspondence to Dr Sucheta Kulkarni; drsucheta. kulkarni@gmail.com

\section{ABSTRACT}

Objective To estimate magnitude of diabetes mellitus (DM) and diabetic retinopathy (DR) in a high risk population in Pune, western India.

Methods DR module in rapid assessment of avoidable blindness (RAAB) survey methodology was used. Sample size of 3527 was calculated based on estimates from previous studies in India. A certified RAAB trainer conducted a training of survey teams. Random cluster sampling with probability proportionate to size was adapted to select 60 clusters consisting of 60 individuals each. Two teams visited door to door until they finished visiting 60 persons each day. Visual acuity testing, torch light examination, red glow test were carried out to determine persons with visual impairment and its cause. Every participant then underwent a random blood sugar level testing. All diabetics (known and newly detected) underwent dilated retina evaluation with indirect ophthalmoscopy to determine their DR status. Data were entered into RAAB6 software and descriptive statistics generated.

Results Response rate was $89.5 \%$ (3221/3600), females $(55.3 \%)$. The prevalence of DM in the sample was $(706 / 3221) 21.9 \%(95 \mathrm{Cl} 20.1$ to 23.7$)$. Prevalence of DR was $14.3 \%$ (95\% Cl 11.7 to 16.9). Most diabetics $(401 / 579,69.3 \%)$ never had an eye examination for DR in the past. Cataract was the principal cause of blindness (50 $\%$ cases) among diabetics.

Conclusion DM affects over fifth of persons above 50 years of age in western India. Nearly seventh of the diabetics have DR, but coverage of screening is poor in Pune.

\section{INTRODUCTION}

India is home to over 74 million diabetics, and the number is estimated to exceed 123 million by $2040 .^{1}$ Increasing longevity, changing lifestyle and dietary habits contribute to increasing prevalence of diabetes mellitus (DM) in India and all over the world. ${ }^{2}$ Largest increase in the disease burden (among all non-communicable diseases) between the year 1996 and 2016 was noted for DM at $80 \% .^{3}$ Diabetes and its complications are now

\section{Significance of the study}

What is already known about this subject?

Available evidence shows an increasing prevalence of diabetes mellitus (DM) and diabetic retinopathy (DR) in India.

\section{What are the new findings?}

This study which is first such in over a decade, reports high prevalence of both DM and DR in a western Indian population with a sizeable proportion of urban poor. It also demonstrates significant proportion of unidentified cases of DM and poor coverage of DR screening in an urban region with good access to healthcare.

\section{How might these results change the focus of} research or clinical practice?

These results emphasise the need of evidence generation on prevalence of DM and DR from rural as well as other urban regions of India and to identify strategies to improve screening coverage for detection of DM and DR.

an area of focus for prevention of mortality and morbidity. Absence of acute symptoms and lack of awareness are the main barriers for detection of DM and its complications. ${ }^{45}$

Prevalence of DM in India has been reported to be between $10.2 \%$ and $36 \%$ in various population-based surveys. ${ }^{6-9}$ However, there was a variation in the age group included and the methodology used in these surveys. A multistate survey to establish prevalence of DM published in 2010 reported age-specific prevalence of DM. Prevalence in population above 55 years of age in Maharashtra state (where present study was conducted) was $25 \%$ for men and $20 \%$ for women. ${ }^{6}$

Diabetic retinopathy (DR) is a microvascular complication of $\mathrm{DM}$ and can cause blindness or visual impairment (VI). Although cataract remains a principal cause 
of blindness in India, other retinal causes (especially DR) are emerging as priority diseases for national programme for control of blindness (NPCB) ${ }^{10}$ as well as vision 2020 India. ${ }^{11}$ Prevalence of DR among diabetics has been reported to be $9.6 \%-21.7 \%$ in various studies conducted across India over the last decade. ${ }^{12-16}$ Previous DR surveys have been conducted largely in south and central India. Also, the age groups included and the methodology used was widely variable making direct comparison impossible. Moreover, there is likely to be a variation in the prevalence across states of India due to differences in levels of urbanisation which can affect lifestyle of the population. This study was conducted in Pune municipal corporation area (population 3 million, $16 \%$ persons $>50$ years of age $)^{17}$ of the Maharashtra state of western India. Pune is the second largest city in the state and is a hub for education, automobile and information technology industry. Due to a sizeable proportion of slum dwellers $(40 \%)$, large migrant population from other states and rapidly changing lifestyle, the population forms a 'high risk' group for DM. There is no available data guiding the implementation of DR services in the city. This study therefore aims to provide a baseline data to plan the DR services in the city to achieve better blindness prevention. In Pune, there are nearly 400 ophthalmologists and over 25 DR screening and treatment centres of which most (24) are in the private sector (personal communication). In India, private expenditure (including out of pocket payments) constitutes $70 \%$ of total health expenditure and $61 \%$ of inpatient episodes or hospital visits are in the private sector. ${ }^{18}$ Where the private sector dominates the health system, the poor struggle to access fee-for-service care. $^{19}$

Rapid assessment of avoidable blindness (RAAB) is a survey methodology designed for assessment of prevalence and causes of blindness and VI in population over 50 years of age. ${ }^{20}{ }^{21}$ It has been used in over 200 population surveys of eye health worldwide. ${ }^{22}{ }^{23}$ Later DR module was added to the original RAAB methodology ${ }^{22}$ which allows estimation of prevalence of DM and DR in a high risk population. This survey was planned with the objectives of estimating prevalence and causes of blindness as well as prevalence of DM and DR in Pune. The findings related to DR module of the survey will be presented in this paper. To the best of the authors' knowledge, this is first such survey in India.

\section{METHODS}

This cross sectional survey used RAAB+DR methodology. Each survey team consisted of an ophthalmologist (minimum 1 year experience of working in the retina department with a focus on DR), an optometrist, a study coordinator and a technician. Three such teams were trained for a week by a certified RAAB trainer. At the end of the training, each team underwent inter observer variability (IOV) testing to check agreement on visual acuity assessment and diagnosis of DR between each team and a gold standard (a senior ophthalmologist). A kappa value of 0.6 or more was considered as acceptable. Kappa values of IOV for visual acuity assessment and DR assessment were 0.87 and 0.65 respectively.

\section{Sampling}

This study was undertaken in Pune municipal area between ${ }^{17}$ June and August 2017. Previous studies in India have estimated the prevalence of DM in the population aged 50 and above at $15 \%^{6713}$ and that $25 \%$ of this group experience DR. ${ }^{14} 15$ A sample size of 3527 participants age 50 and above was calculated based on an expected prevalence of DR of $3.8 \%{ }^{14}$ in general population of this age group, precision of $22 \%$ of the estimate $(0.84 \%)$ (considering the time, logistics and seasonality of area in order that survey could be completed yielding valid results.), non-compliance of $10 \%, 95 \%$ confidence and a design effect of 1.6.

Therefore, 60 clusters consisting of 60 participants each needed to be examined. Clusters were selected using probability proportionate to size sampling (cluster with a higher population had more chance of getting selected). Updated data from the electoral list of 2017 was used as the sampling frame. The detailed methods of RAAB +DR are presented elsewhere. ${ }^{22}{ }^{23}$ Each cluster was divided into multiple segments each having approximately 60 persons above 50 years of age (compact segment sampling). Local community leaders helped in segmentation and random selection of a segment using a folded chit lottery method. The survey coordinator publicised the date and time of visit at least a day prior to minimise non-response. Two teams then visited separate areas (door to door visit) in the segment until they examined 30 persons each. If an enumerated person was not available, the team made a repeat visit at the end of the day to check the availability. In the selected segments having high rise apartments, each consecutive house was visited until target of 30 enumerations was achieved by each team.

\section{Examination and data collection}

Data on occupational and health insurance status were collected in the two additional fields provided in the standard RAAB data forms. All participants then underwent presenting and pinhole visual acuity testing in each eye using Snellen's tumbling E chart. Participants were labelled as having normal vision, early/moderate/severe VI or blindness as per WHO's convention and the RAAB survey methodology V.6. All participants then underwent anterior segment evaluation with a light source, and a brief lens examination for red glow by direct ophthalmoscope. All eyes with early VI $(<6 / 12)$ or worse were examined with a torch and a direct ophthalmoscope (in a darkened room in the house of the participant) to ascertain the cause. In the participants who were not dilated, if no anterior segment or obvious posterior segment cause was identified, eyes were labelled as having other posterior segment disease. 
Following WHO convention, the principal cause of VI/ blindness was defined as the disorder most amenable to treatment or prevention. ${ }^{24}$ If there was a primary and a secondary cause, the primary cause was selected as the principal disorder. ${ }^{25}$ For example, participants with VI resulting from cataract and other disease (such as DR) were labelled as having cataract as the primary cause.

All participants who consented then underwent a random blood sugar level (RBSL) test. Self-reported diabetics and those with RBSL of $\geq 200 \mathrm{mg}$ (newly diagnosed diabetics) were examined for DR after pupillary dilatation. Retinal examination was carried out with indirect ophthalmoscope (Appasamy Associates, Chennai, India) and 20D lens (Volk, Germany) after a minimum $30 \mathrm{~min}$ of dilatation. Meanwhile survey team continued visiting other houses for data collection before coming back to perform indirect ophthalmoscopy in dilated individuals. Assessment of DR was completed by a trained ophthalmologist. The Scottish classification was used for grading retinopathy and maculopathy. ${ }^{26}$ Those with proliferative changes and macular oedema involving the centre were classified as having sight threatening DR (STDR). All self-reported diabetics were asked about the timing of last retina evaluation in order to determine DR screening coverage. All participants identified with a treatable cause of blindness or VI were referred to the base hospital for further management.

\section{Data entry and analysis}

Data were entered into the RAAB6 software on a daily basis by two separate data entry operators (double entry) to ensure validity and consistency. Descriptive statistics were generated by RAAB6 software. Statistical tests of association were carried out in a statistical software (STATA IC V.14, StataCorp).

\section{RESULTS}

The response rate was $89.5 \%$ (3221/3600), 55.3\% were females. Gender representation in the age group 50-59 years was $41.9 \%(604 / 1440)$ men vs $47.2 \%$ (841/1781) women. In other age group categories, characteristics of respondents such gender were equally distributed. Among respondents, a further 6\% (203/3600) who were not known diabetics refused blood test-most of these
$(173 / 203,85.2 \%)$ being from younger age group of 50-59 years.

The prevalence of DM in the sample was $(706 / 3221)$ $21.9 \%$ (95 CI 20.1 to 23.7). Prevalence of DM by age and gender is shown in table 1 .

Of the total 706 diabetics, $127(18 \%)$ were newly identified. Of the 579 self-reported diabetics, 256 (44.2\%) had RBSL of $>200 \mathrm{mg} / \mathrm{dL}$. Coverage of treatment for DM was $96.4 \%$ (558/579). Most $(514 / 579,88.8 \%)$ were on oral hypoglycaemic drugs. Twenty one $(3.6 \%)$ did not receive any antidiabetic treatment.

DR screening coverage: most diabetics $(401 / 579,69.3 \%)$ never had a screening for DR in the past and 19\% $(110 / 579)$ had one in last 12 months.

Nearly a third $(237 / 706,33 \%)$ diabetics refused to undergo dilatation required to determine status of DR. The data were stratified by occupational status (daily wage workers vs fixed income/business) and health insurance status (yes/no). There was a very strong evidence to suggest that daily wage workers and uninsured persons were less likely to undergo DR screening compared with others $(\mathrm{p}<0.001)$.

Prevalence of any retinopathy/maculopathy among diabetics was $14.3 \%$ (95\% CI 11.7 to 16.9 ) and that of STDR was $3.1 \%$ (95\% CI 1.9 to 4.3 ). The proportion of dilated participants who had any sign of retinopathy/ maculopathy was $21 \%$, STDR was $3.1 \%$ and that of lasered DR was $2.7 \%$. Prevalence by grades of DR among diabetics and in full sample is shown in table 2.

Prevalence of VI and blindness among diabetics is shown in table 3.

Causes of blindness and VI among diabetics are shown in table 4.

All data relevant to the study are included in the article or uploaded as supplementary information (online supplementary files 1-8).

\section{DISCUSSION}

India is one of the top two countries with high number of persons with DM. ${ }^{1}$ Estimating prevalence of DM and DR is vital to planning, monitoring services and allocating resources for the same. Estimating proportion of diabetics in general population is possible only in a population-based survey and entails high cost and investment

\begin{tabular}{|c|c|c|c|c|c|c|}
\hline \multirow[b]{2}{*}{ Age (years) } & \multicolumn{2}{|l|}{ Men } & \multicolumn{2}{|c|}{ Women } & \multicolumn{2}{|l|}{ Total } \\
\hline & $\mathbf{N}$ & $\%(95 \% \mathrm{Cl})$ & $\mathbf{N}$ & $\%(95 \% \mathrm{Cl})$ & $\mathrm{N}(\%)$ & $95 \% \mathrm{Cl}$ \\
\hline $50-59$ & 115 & 19.0 (15.8 to 22.3 ) & 157 & 18.7 (16.0 to 21.4 ) & 272 & 18.8 (16.7 to 20.9 ) \\
\hline $60-69$ & 128 & 25.5 (21.2 to 29.9 ) & 158 & 26.2 (22.5 to 29.9 ) & 286 & 25.9 (23.2 to 28.6$)$ \\
\hline $70-79$ & 64 & 26.0 (19.9 to 32.2) & 57 & 24.5 (17.9 to 31.0$)$ & 121 & 25.3 (20.4 to 30.1$)$ \\
\hline $80+$ & 15 & 16.9 (10.3 to 23.4$)$ & 12 & 11.5 (6.5 to 16.6$)$ & 27 & 14.0 (9.8 to 18.2$)$ \\
\hline All ages & 322 & 22.4 (19.7 to 25.0$)$ & 384 & 21.5 (19.3 to 23.8 ) & 706 & 21.9 (20.1 to 23.7$)$ \\
\hline
\end{tabular}

*Known and newly diagnosed diabetes mellitus. 
Table 2 Prevalence of DR in diabetics and in entire sample

\begin{tabular}{|c|c|c|c|}
\hline & & Among diabetics & Full sample \\
\hline Retinopathy grade & $\mathbf{n}$ & $\mathrm{P}$ value $(95 \% \mathrm{Cl})$ & $\mathrm{P}$ value $(95 \% \mathrm{Cl})$ \\
\hline No retinopathy $(\mathrm{R} 0)$ & 379 & $53.7 \%(49.4$ to 58.0$)$ & $11.8 \%$ (10.4 to 13.2 ) \\
\hline Background DR-mild (R1) & 50 & $7.1 \%(5.2$ to 8.9$)$ & $1.6 \%(1.1$ to 2.0$)$ \\
\hline Background DR-observable (R2) & 11 & $1.6 \%(0.7$ to 2.4$)$ & $0.3 \%(0.2$ to 0.5$)$ \\
\hline Background DR-referable (R3) & 13 & $1.8 \%(0.6$ to 3.0$)$ & $0.4 \%(0.1$ to 0.7$)$ \\
\hline Proliferative DR (R4) & 14 & $2.0 \%(1.1$ to 2.9$)$ & $0.4 \%(0.2$ to 0.6$)$ \\
\hline Ungradable DR (R6) & 4 & $0.6 \%(0.0$ to 1.1$)$ & $0.1 \%(0.0$ to 0.2$)$ \\
\hline Any retinopathy & 92 & $13.0 \%(10.7$ to 15.4$)$ & $2.9 \%(2.3$ to 3.4$)$ \\
\hline \multicolumn{4}{|l|}{ Maculopathy grade } \\
\hline No maculopathy (M0) & 408 & $57.8 \%$ (53.5 to 62.1$)$ & $12.7 \%(11.2$ to 14.1$)$ \\
\hline Maculopathy-observable (M1) & 35 & $5.0 \%(3.5$ to 6.4$)$ & $1.1 \%(0.8$ to 1.4$)$ \\
\hline Maculopathy-referable (M2) & 17 & $2.4 \%(1.4$ to 3.5$)$ & $0.5 \%(0.3$ to 0.8$)$ \\
\hline Any maculopathy & 63 & $8.9 \%$ (6.9 to 11.0$)$ & $2.0 \%(1.5$ to 2.4$)$ \\
\hline Any retinopathy/maculopathy & 101 & $14.3 \%(11.7$ to 16.9$)$ & $3.1 \%(2.5$ to 3.7$)$ \\
\hline Sight-threatening DR (R4 and/or M2) & 22 & $3.1 \%(1.9$ to 4.3$)$ & $0.7 \%(0.4$ to 0.9$)$ \\
\hline Any laser scars & 19 & $2.7 \%$ (1.5 to 3.8$)$ & $0.6 \%$ (0.3 to 0.8$)$ \\
\hline
\end{tabular}

DR, diabetic retinopathy.

of resources and time. Adding DR module to a proven methodology of $\mathrm{RAAB}$ reduces the sample size without greatly affecting the accuracy of estimates.

Although response rate was good in the present study, there was slight over-representation of women especially in the younger (50-59 years) age group. This was because more men were away at work and hence unavailable on the day of survey.

Over one fifth $(21.9 \%)$ of the participants had DM which extrapolates to 132000 persons above 50 years of age having DM in Pune. Nearly $18 \%$ newly detected DM cases gives an estimate of 80000 undetected cases of DM in Pune. However, there is a possibility of overestimation of prevalence as $6 \%$ persons without known diabetic status refused BSL examination. There was no significant difference in prevalence by gender. This proportion is higher than findings in previous studies from India. ${ }^{671213}$ The difference in the age groups of study sample may partly explain the higher prevalence in this study. A study conducted in south India ${ }^{14}$ in population over 40 years had shown higher prevalence (28.2\%). Different dietary habits in south India compared with western India might explain higher prevalence in that study. Prevalence of DM increased with increasing age up to 79 years thereafter falling down to a tenth. Wide $95 \%$ CI in $80+$ age group indicates inadequate sample size and hence variable prevalence. Of the participants with DM, nearly a fifth were not aware of their status and almost half had uncontrolled BSL. This emphasises the need to create awareness of DM, improve access to diagnostic services for DM and DR especially in public hospitals for better case detection. Previous studies from India have reported poor awareness about DM among general population. ${ }^{45}$ Persons with DM also need to be educated about importance of BSL control in reducing the risk of complications of DM.

Among known diabetics, coverage for treatment of DM was good $(96.7 \%)$ but that for DR screening was poor. Over two-thirds of known diabetics had never received any eye examination for DR. Only a fifth had received DR screening in last 12 months. Indian guidelines recommend at least once a year retinal evaluation

\begin{tabular}{|c|c|c|c|c|}
\hline & \multicolumn{2}{|c|}{ Persons with diabetes } & \multicolumn{2}{|c|}{ Persons without diabetes } \\
\hline & $\mathbf{n}$ & $\%(95 \% \mathrm{Cl})$ & $\mathbf{n}$ & $\%(95 \% \mathrm{Cl})$ \\
\hline Normal vision & 494 & 70.0 (65.2 to 74.7$)$ & 1719 & $68.3(65.7$ to 71.0$)$ \\
\hline Early VI & 114 & $16.1(12.9$ to 19.4$)$ & 365 & $14.5(12.9$ to 16.1$)$ \\
\hline Moderate VI & 84 & 11.9 (9.2 to 14.6$)$ & 356 & $14.2(12.2$ to 16.1$)$ \\
\hline Severe VI & 8 & $1.1(0.1$ to 2.1$)$ & 35 & $1.4(1.0$ to 1.8$)$ \\
\hline Blindness & 3 & $0.4(0.0$ to 0.9$)$ & 24 & $1.0(0.5$ to 1.4$)$ \\
\hline
\end{tabular}

VI, visual impairment. 
Table 4 Causes of visual impairment among people with and without diabetes

\begin{tabular}{|c|c|c|c|c|c|c|c|c|}
\hline & \multicolumn{2}{|c|}{ Blindness } & \multicolumn{2}{|c|}{ Severe VI } & \multicolumn{2}{|c|}{ Moderate VI } & \multicolumn{2}{|l|}{ Early VI } \\
\hline & DM & Non-DM & DM & Non-DM & DM & Non-DM & DM & Non-DM \\
\hline & n (\%) & n (\%) & n (\%) & n (\%) & n (\%) & n (\%) & n (\%) & n (\%) \\
\hline Refr. error & $0(0)$ & $1(2)$ & $0(0)$ & $1(2)$ & $12(14)$ & 47 (13) & $46(40)$ & 168(46) \\
\hline Cataract & $3(50)$ & $18(45)$ & $8(100)$ & $26(74)$ & $57(67)$ & $236(66)$ & $50(43)$ & $152(41)$ \\
\hline DR & $0(0)$ & $0(0)$ & $0(0)$ & $0(0)$ & $3(3)$ & $0(0)$ & $0(0)$ & $0(0)$ \\
\hline PSD & $1(16)$ & $17(42)$ & $0(0)$ & $3(8)$ & 7 (8) & 37 (10) & $9(7)$ & $18(4)$ \\
\hline Other & 2 (33) & $4(10)$ & $0(0)$ & $5(14)$ & $5(5)$ & $36(10)$ & $9(7)$ & $27(7)$ \\
\hline Total & $6(100)$ & 40 (100) & 8 (100) & 35 (100) & 84 (100) & $356(100)$ & 114(100) & 365 (100) \\
\hline
\end{tabular}

DM, diabetes mellitus; DR, diabetic retinopathy; PSD, posterior segment disorder.

for all diabetics. ${ }^{11}$ There was a very strong evidence to suggest that daily wage workers and uninsured persons were less likely to undergo DR screening. Screening for $\mathrm{DR}$ is a form of preventive health check-up available for a fees, hence persons belonging to lower socioeconomic strata were more likely to avoid it. Excellent coverage of treatment for DM indicates that people chose to receive medications for DM irrespective of socioeconomic status. This suggests that cost and lack of awareness could be important barriers for DR screening. Educating primary healthcare professionals such as physicians, general practitioners, pharmacists, laboratory personnel about the need and protocol for DR screening is perhaps the key to improve coverage of DR screening. Establishing DR screening programmes at diabetes clinics rather than at specialist eye hospitals might also help to improve screening coverage further.

Extrapolation of prevalence figures of DR (14.3\%) and STDR (3.1\%) among diabetics suggests, there are likely to be approximately 19000 persons with DR and 5000 with STDR in Pune. Some participants refused to be dilated, hence these are likely underestimates. In a recent publication, Flaxman et $a t^{27}$ have reported that globally crude prevalence (all age) of blindness due to all causes showed a declining trend except for DR which showed $7.7 \%$ increase. There was no statistically significant difference between prevalence of blindness and VI among diabetics and non-diabetics in this study. This could be because of good accessibility of services in this densely populated urban region.

Cataract was the principal cause of blindness $(50 \%$ cases) followed by other posterior segment disorders (16\%) among diabetics. This proportion among non-diabetics was $45 \%$ and $42 \%$ respectively. Risk of cataract among diabetics is higher than non-diabetics which could have been responsible for cataract being assigned as cause of blindness among them. DR as a cause of moderate VI was seen in $3 \%$ of diabetics. The causes of VI did not differ by DM status of the participants. None of the diabetic subjects was blind due to DR. However, this study was not powered enough to estimate prevalence of STDR. Additionally, there is a possibility of underestimation of DR as a cause of blindness/VI in diabetics as the disease most amenable to treatment (such as cataract) was labelled as the principal cause as per WHO convention.

There are certain limitations to this study. Over-representation of women especially in the younger age group could have resulted in selection bias. Every 1 in 20 participants refused RBSL test leading to possible overestimation of prevalence of DM. Nearly a third of diabetics refused dilated eye examination, adding potential downward bias to results. Conversely, the use of field-appropriate methods of diagnosis and grading may have led to an upward bias of results compared with a higher-end clinic-based equipment. Further analysis of known diabetics by their medication and DM control status would have helped study association between DR/ STDR and DM control.

There is a definite need to increase awareness of DM among general population which will help in identifying a greater proportion of diabetics. Targeting diabetes clinics and use of telemedicine will improve coverage of DR screening. Referral linkages need to be established between diabetes clinics and DR treatment centres. There is need of similar RAAB plus DR survey in rural population as prevalence is known to differ. ${ }^{6}$ Similar surveys in other parts of the state/country might fetch different results due to wide variation in dietary habits, lifestyles and are the need of the hour.

It is recommended that all stake holders be involved in increasing awareness, improving screening coverage and establishing referral linkages between screening and treatment centres. The findings of this study were disseminated through a meeting involving important stakeholders such as chief municipal health officer, district ophthalmic surgeon, secretary of the local branch of the Indian Medical Association, presidents of the local 'Diabetes Association' and senior citizen association etc. Results were also publicised through local print and electronic media to generate awareness about screening and treatment facilities. For improving access to DR treatment, a plan to link screening facilities in public sector to the treatment facilities in charitable organisations was submitted to municipal health authorities. 
In conclusion, DM affects over fifth of persons above 50 years of age in urban India. Every seventh person with DM has DR, but coverage of screening is poor in Pune.

Acknowledgements Authors would like to acknowledge following people: Mr Nitin Desai, Chairman, Desai Brothers Pvt. Ltd. for supporting this research and free services for patients identified through this research. Sandip Anjankar and the entire RAAB team of H. V. Desai Eye Hospital for the field work, Sarah Wallace for active participation and valuable inputs during dissemination meeting.

Contributors SK: concept, implementation, data analysis and interpretation, writing manuscript, submission of the manuscript. SK: implementation, data collection, analysis, interpretation, writing manuscript. IM, BRS: implementation, data analysis, interpretation, critical review of the manuscript. AL, RM: implementation, data collection, interpretation, critical review of the manuscript. JK: implementation, data collection, critical review of the manuscript. RK, KD, DM: implementation, interpretation of data, critical review of the manuscript.

Funding Grant for this survey was provided by Desai Brothers Pvt. Ltd, Pune, India.

Competing interests None declared.

Patient consent for publication Not required.

Ethics approval Ethics committee of PBMA's H. V. Desai Eye hospital, Pune approved this study (Ref. no. HVD/EC/48/2016).

Provenance and peer review Not commissioned; externally peer reviewed.

Author note This manuscript has not been published or been submitted simultaneously to any other journal.

Open access This is an open access article distributed in accordance with the Creative Commons Attribution Non Commercial (CC BY-NC 4.0) license, which permits others to distribute, remix, adapt, build upon this work non-commercially, and license their derivative works on different terms, provided the original work is properly cited, appropriate credit is given, any changes made indicated, and the use is non-commercial. See: http://creativecommons.org/licenses/by-nc/4.0/.

\section{REFERENCES}

1. International Diabetes Federation, 2015. Prevalence and magnitude of diabetes as per country/region. Available: http://www. diabetesatlas.org/resources/2015-atlas.html [Accessed 15 Jun 2018].

2. Goff LM, Duncan A. Diet and lifestyle in the prevention of the rising diabetes pandemic. J Hum Nutr Diet 2010;23:333-5.

3. Department of Health Research Govt of India, 2017. India: Health of the Nation's states. Available: http://www.healthdata.org/sites/ default/files/files/policy_report/2017/India_Health_of_the_Nation\% 27s_States_Report_2017.pdf [Accessed 15 Jun 2018].

4. Lingam S, Rani PK, Sheeladevi S, et al. Knowledge, attitude and practices on diabetes, hypertension and diabetic retinopathy and the factors that motivate screening for diabetes and diabetic retinopathy in a pyramidal model of eye health care. Rural Remote Health 2018;18.

5. Hussain R, Rajesh B, Giridhar A, et al. Knowledge and awareness about diabetes mellitus and diabetic retinopathy in suburban population of a South Indian state and its practice among the patients with diabetes mellitus: a population-based study. Indian $J$ Ophthalmol 2016;64:272-6.

6. Anjana RM, Pradeepa R, Deepa M, et al. Prevalence of diabetes and prediabetes (impaired fasting glucose and/or impaired glucose tolerance) in urban and rural India: phase I results of the Indian Council of medical Research-INdia diabetes (ICMR-INDIAB) study. Diabetologia 2011:54:3022-7.

7. Prasad DS, Kabir Z, Dash AK, et al. Prevalence and risk factors for diabetes and impaired glucose tolerance in Asian Indians: community survey from urban eastern India. Diabetes \& Metabolic Syndrome: Clinical Research \& Reviews 2012;6:96-101.

8. Radhakrishnan S, Balamurugan S. Prevalence of diabetes and hypertension among geriatric population in a rural community of Tamilnadu. Indian J Med Sci 2013;67:130-6.

9. Rajput R, Rajput M, Singh J, et al. Prevalence of diabetes mellitus among the adult population in rural blocks of Haryana, India: a community-based study. Metab Syndr Relat Disord 2012;10:443-6.

10. Vemparala R, Gupta P. National Programme for control of blindness (NPCB) in the 12th five year plan: an overview. DJO 2017;27:290-2.

11. Vision 2020 India, 2008. Guidelines for the comprehensive management of Dr in India. Available: https://www.iapb.org/wpcontent/uploads/Guidelines-for-the-Comprehensive-Managementof-DR-in-India.pdf [Accessed 10 Jun 2018].

12. Jonas JB, Nangia V, Khare A, et al. Prevalence and associated factors of diabetic retinopathy in rural central India. Diabetes Care 2013;36:e69.

13. Namperumalsamy P, Kim R, Vignesh TP, et al. Prevalence and risk factors for diabetic retinopathy: a population-based assessment from Theni district, South India. Br J Ophthalmol 2009;93:429-34.

14. Raman R, Rani PK, Reddi Rachepalle S, et al. Prevalence of diabetic retinopathy in India: Sankara Nethralaya Diabetic Retinopathy Epidemiology and molecular Genetics study report 2. Ophthalmology 2009;116:311-8.

15. Rema M, Premkumar S, Anitha B, et al. Prevalence of diabetic retinopathy in urban India: the Chennai urban rural epidemiology study (cures) eye study, I. Invest Ophthalmol Vis Sci 2005;46:2328-33.

16. Gadkari S, Maskati Q, Nayak B. Prevalence of diabetic retinopathy in India: the All India Ophthalmological Society diabetic retinopathy eye screening study 2014. Indian J Ophthalmol 2016;64:38-44.

17. Census Organization of India, 2011. Population census of India 2011 [census organization website]. Available: http://www.census2011.co. in/census/city/375-pune.html [Accessed June 15, 2017]

18. Nandi S, Schneider H, Dixit P. Hospital utilization and out of pocket expenditure in public and private sectors under the universal government health insurance scheme in Chhattisgarh state, India: lessons for universal health coverage. Plos One 2017; 12:e0187904-18

19. Mackintosh M, Channon A, Karan A, et al. What is the private sector? understanding private provision in the health systems of low-income and middle-income countries. The Lancet 2016;388:596-605

20. Dineen B, Foster A, Faal H. A proposed rapid methodology to assess the prevalence and causes of blindness and visual impairment. Ophthalmic Epidemiol 2006;13:31-4.

21. Kuper $\mathrm{H}$, Limburg $\mathrm{H}$, Polack $\mathrm{S}$. Rapid assessment of avoidable blindness. J Ceh 2006;19.

22. Polack S, Yorston D, López-Ramos A, et al. Rapid assessment of avoidable blindness and diabetic retinopathy in Chiapas, Mexico. Ophthalmology 2012;119:1033-40.

23. Zatic T, Bendelic E, Paduca A, et al. Rapid assessment of avoidable blindness and diabetic retinopathy in Republic of Moldova. $\mathrm{Br} J$ Ophthalmol 2015;99:832-6.

24. World Health Organization, 2010. Blindness and Low Vision [WHO website]. 10th revis. ICD-10 International Statistical Classification of Diseases and Related Health Problems. Available: http://www.who. int/classifications/icd/ICD10Volume2 en_2010.pdf [Accessed 15 May 2017]

25. World Health Organization, 1988. Coding Instructions for the WHO/PBL eye examination record (version III). Geneva: PBL/88.1. Available: http://www.who.int/iris/handle/10665/67896 [Accessed May 5, 2018].

26. Scottish Diabetic Retinopathy Screening Collaborative, 2007. Scottish Diabetic Retinopathy grading scheme 2007 v1.1 [NHS Scotland website]. Available: http://www.ndrs-wp.scot.nhs.uk/ wp-content/uploads/2013/04/Grading-Scheme-2007-v1.1.pdf [Accessed April 11, 2017].

27. Flaxman SR, Bourne RRA, Resnikoff $S$, et al. Global causes of blindness and distance vision impairment 1990-2020: a systematic review and meta-analysis. Lancet Glob Heal 2017;5:e1221-34. 